\title{
Intellectual Quotient and Social Cognition in Young Offenders: A Relational Analysis
}

\author{
Catalina Quintero-Lopez ${ }^{1}$, Victor Daniel Gil-Vera ${ }^{1}$, Andrés Felipe Velez-Vásquez ${ }^{2}$, Elizabeth Zapata-Lopez ${ }^{2}$, \\ Luisa Fernanda Sepulveda ${ }^{2} \&$ Luis Eduardo de Angel Martinez ${ }^{3}$ \\ ${ }^{1}$ NBA Research Group, Universidad Catolica Luis Amigo, Medellin, Colombia \\ ${ }^{2}$ Universidad Catolica Luis Amigó, Medellín, Colombia \\ ${ }^{3}$ Centro de Atención al Joven Carlos Lleras Restrepo, Medellin, Colombia \\ Correspondence: Catalina Quintero-Lopez, NBA Research Group, Universidad Católica Luis Amigó, Medellin, \\ Colombia.
}

Received: September 30, 2020

Accepted: October 21, $2020 \quad$ Online Published: November 10, 2020

doi:10.5539/mas.v14n12p16

URL: https://doi.org/10.5539/mas.v14n12p16

\begin{abstract}
Antisocial personality disorder (ASPD) showed a broad executive function, as well as visual short-term, working memory (WM), and attention deficits. The inhibitory control and WM deficits may distinguish ASPD from other personality disorders. People with ASPD structure have deficiencies in the maturation of the prefrontal cortex which is evident in various neurocognitive problems, mainly in WM and social cognition (SC). In Colombia there is a high incidence of ASPD in young offenders, which makes the process of rehabilitation and resocialization more difficult. The aim of this paper was to develop a structural equation model (SEM) to identify the relationship between SC and intellectual quotient (IQ) in offenders with ASPD and make a comparative analysis by gender. A representative sample of 120 offenders was used (60 men and 60 women) of a Specialized Attention Center (SAC) in Medellin, Colombia. This paper concludes that there is a higher correlation between SC and IQ in women offenders with ASPD $(\sigma x y=0.62)$ than in male offenders with ASPD $(\sigma x y=0.54)$. Epidemiologists suggest that women have a high prevalence of depressive and anxiety disorders, which can be explained by internalized behavioral management. In general, men show a higher prevalence of disorders associated with impulse control through externalizing behavioral management. This shows that ASPD has been studied more in men and that ASPD profiles in women are lacking due to its low prevalence. Based on the results of the model developed, a neurocognitive profile of men and women with ASPD is presented.
\end{abstract}

Keywords: ASPD, SEM, gender, cognition, behavior

\section{Introduction}

People with ASPD who do not differentiate between right or wrong and ignore the rights and feelings of others, tend to harass, manipulate or treat others with cruelty or indifference and feel no guilt or remorse for their behavior. Most of them tend to break the law and become criminals. They tend to lie, be more violent and impulsive and more common to have drugs and alcohol addictions. Indeed, in many cases these people are unable to work, have poor academic performance and social activities (Mayo Clinic, 2020). ASPD was associated with difficulties in attention, executive functions (WM and SC). The deficits noted in visual search, inhibitory control, response reversal, and WM are very defined in patients with ASPD, those appeared pronounced in ASPD relative to patients with other personality disorders (Baliousis et al., 2019).

$\mathrm{SC}$ is a vital part of social interaction that involves the processing of complex mental states and other social stimuli prior to producing an appropriate response. It is essential for interpersonal relationships and for mental well-being. Individual and group differences exist in social cognition. Difficulties in aspects of SC such as emotion recognition and "theory of mind", the ability to imagine other people's thoughts and feelings and to use such information to make sense of and predict another person's behavior, can cause difficulties in social interaction and these can contribute to some mental health conditions. Different aspects of SC (face recognition, emotion recognition, cognitive empathy, and affective empathy) are impaired in different clinical conditions (autism, attention deficit, dementia and ASPD). The difficulties in SC may be camouflaged in individuals who acquire compensatory coping strategies as adults. A good test of SC, in addition to quantifying individual differences in the general population, 
needs to address two issues: it must be specific to identify differences between various psychiatric conditions and be sensitive enough to identify subtle differences between individuals who may have learned compensatory strategies (Warrier \& Baron, 2017).

The objective of this paper was to propose and test a hypothetical Structural Equation Model (SEM) to explore interrelationships between factors predictive of ASPD in young offenders. The results from two psychometric tests related to SC (Screw-up test and Eye test) and four tests related to IQ (verbal comprehension -VC, perceptual reasoning PR, WM and processing speed - PS) were used. The model was developed with two latent variables (CS) and (IQ). The statistical software STATA 16 and Rstudio was used for the modelling. Two independent models were developed (men and women).

The results showed that there are significant differences between both genders. The correlation is higher in women offenders with ASPD. There are differences between the neurocognitive profile of antisocial men and women. Antisocial men showed to have higher IQs than women, men showed better results in WM rates, perceptive reasoning and speed of information processing. Women performed better on the $\mathrm{VC}$ index. Associated to SC both have very similar characteristics, they show deficiencies at the level of prefrontal cortex myelination, women have more difficulties recognizing expressions of fear and anguish, but men showed to have more difficulties in recognizing expressions associated to irritability, aggressiveness and violence.

\section{Literature Review}

The ASPD is a widespread pattern of disregard for the rights of others, which manifests itself as violence, manipulation, deception and aggressive behaviour (Kaya et al., 2020), is a mental illness of great concern worldwide. Post-traumatic stress disorder and association with antisocial partners are associated with an increased risk for the diagnosis of ASPD. Post-Traumatic Stress Disorder in Adolescence Increases the Likelihood of Developing ASPD (Wojciechowski, 2019). ASPD is a serious personality disorder with associations to homicide and violence, but its etiology is not precisely known (DeLisi et al., 2019).

This mental illness and psychopathy attempt to represent individuals demonstrating sensitivity and disregard for others. ASPD has been criticized for capturing a heterogeneous population while missing the essence of the diagnosis by neglecting interpersonal/affective deficits, which includes measures of psychopathy (Baliousis et al., 2019). Impulsivity impacts multiple life domains and is related to criminal and problematic behaviors. Impulsivity and aggression are often associated with psychiatric issues. Personality disorders are related to worse prognosis, increased relapse, and damage to relationships (Baliousis et al., 2019). Antisocial behavior can be processed in many ways, such as aggressive behavior, illegal or deviant behavior, or clinical disorders such as ASPD and related constructs like psychopathy (Ogilvie et al., 2011).

ASPD is described in the 5th edition of the Diagnostic and Statistical Manual of Mental Disorders (DSM-V) of the American Psychiatric Association as a pattern of non-compliance with social norms due to repetitive illegal behaviors that result in loss of freedom, are named by an alias, and are characterized by cheating, scamming, lying for profit or pleasure. In addition, they are impulsive, irritable, aggressive, irresponsible and have no guilty feelings when they cause harm to others. Young offenders with an antisocial structure have alterations in social cognition, which is reflected in the difficulty of interacting with others in an appropriate way and putting themselves in the other's place as an empathic symbol (Kratcoski et al., 2020). The offender with an antisocial structure has a different neurobiological functioning than the non-clinical population (Quintero-López et al.,2020), specifically in the brain areas associated with the responses of empathy, sympathy and moral reasoning, here, pleasant biological responses are activated in situations that generate feelings of compassion and pain in the majority of the population (Lebuda et al., 2019). Empathy and sympathy form part of the social neurosciences that are closely intertwined. It is possible to elucidate the affective state of anxiety or distress in order to explain the behavior of individuals, thus understanding prosocial or antisocial behaviors in order to obtain responses associated with emotions such as pain, pity and desire to alleviate suffering (Warrier et al., 2018).

\section{Methodology}

SEM can be used to identify "relationships" between variables, this is a class of multivariate models used for learning a causal relationship among variables or for testing whether the model is best fit by given data. These models analyze latent and observable variables, while their relationships are explained by a linear model whose parameters explain the cause or influence from one variable to another (Pruttiakaravanich \& Songsiri, 2020). SEM has been widely used in psychology and sociology research (Mclntosh \& Gonzalez-Lima, 1994; Price, Laird, Fox, \& Ingham, 2009). In this work we analyzed the relationships between two latent variables (SC and IQ) and six observed variables (Missrep-test, Eye test, VC, PR, WM and PS), which enables you to analyze sportsmans' attitudes in the social cognition. The data used met the scores of a specialized test of 60 men and 60 women, all law 
offenders. Non-probable or purposeful sampling was used. We used multivariate statistical techniques; regression and factor analysis in the statistical software STATA 16 and Rstudio libraries Lavaan, SemPlot, SemTools, GGPlot, CorrPlot and Ggally were used. The dataset gathered the IQ scores of the BAS test (VC, PR, WM and PS and the Misstep-test and Eye test scores. ASPD can be predicted by IQ and by SC. Table 1 presents the variables used in the model:

Table 1. Variables

\begin{tabular}{llll}
\hline Observed Variables & & Construct & Latent variables \\
\hline Misstep-test & X1 & Social cognition & \\
Eye test & X2 & & ASPD \\
VC & X3 & & \\
PR & X4 & \\
WM & X5 & Intellectual coefficient & \\
PS & X6 & & \\
\hline
\end{tabular}

Source: authors elaboration

Table 2 presents the presents the demographic information of the sample:

Table 2. Demographic information

\begin{tabular}{llll}
\hline Demographic characteristic & Frequency & Percentage \\
\hline \multirow{2}{*}{ Gender } & Male & 60 & $50 \%$ \\
& Female & 60 & $50 \%$ \\
& 18 & 25 & $20.83 \%$ \\
\multirow{2}{*}{ Age } & 19 & 15 & $12.50 \%$ \\
& 20 & 75 & $62.50 \%$ \\
& 21 & 5 & $4.17 \%$ \\
& Total & 120 & $100 \%$
\end{tabular}

Source: authors elaboration

Figure 1 presents the hypothetical model

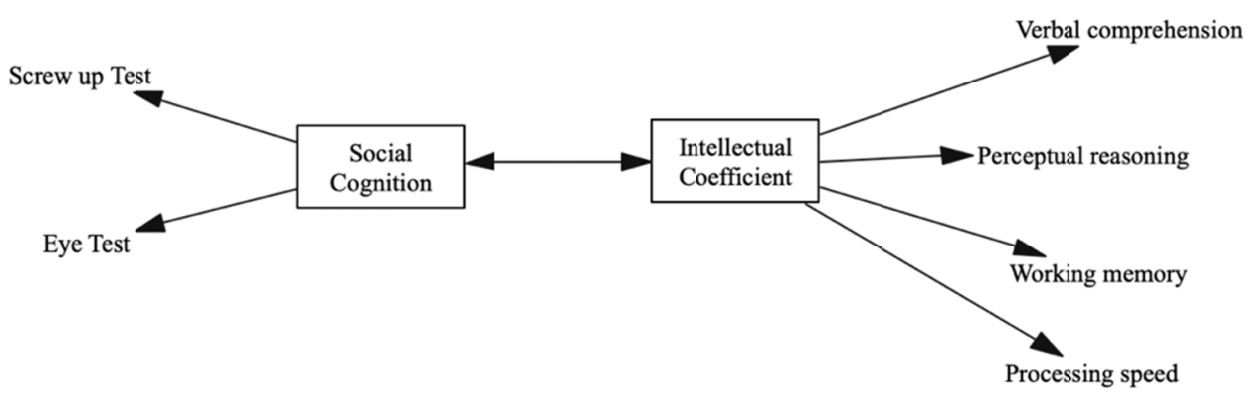

Figure 1. Hypothetical model. Source: authors elaboration

The hypothesis that was studied: H1. There is a strong and direct correlation between SC and IQ in young offenders. The SemModel code used was:

$>$ SemModel <- ' \# regressions

SocialCognition $\sim$ IntellectualCoefficient

\# latent variable definitions 


$$
\begin{aligned}
& \text { SocialCognition }=\sim \mathrm{SUT}+\mathrm{ET} \\
& \text { IntellectualCoefficient }=\sim \mathrm{VC}+\mathrm{PR}+\mathrm{WM}+\mathrm{PS}
\end{aligned}
$$

Next, the conceptualization of the latent and observed variables that were analyzed in the model will be briefly explained. SC includes the ability to represent other people's intentions and beliefs, and the ability to share and recognize the emotions of others (Di Tella et al., 2020). Here, the main aim was to assess the possible presence of gender differences across four aspects of SC: (1) VC, (2) PR, (3) WM and (4) PS. The SC capacities refer to the set of information and procedures committed to the establishment of satisfactory and appropriate social collaborations. Specifically, they allow the recognition of feelings in others, passionate encounters properly adjusted to social circumstances, and the ability to derive mental states into one self and others (Mirabel et al., 2020). BSA is hampered by countless neurological pains, including neurodegenerative diseases, neuropsychiatric problems, and neurodevelopmental conditions, and has become a noteworthy component in differential determinations (Duclos et al., 2018). The connection between academic work and criminal guilt includes an impressive concentration in writing. While there are still jokes regarding the presence of this relationship, there is a broader agreement that people working below the normal level receive an uneven conversation within the prison population (Freeman, 2012). People with a lower than normal IQ at work can be considered a defenseless group for a number of reasons, including academic, professional and social impediments (Freeman, 2012).

$\mathrm{VC}$ alludes to a person's ability to get etymological materials, such as newspapers, magazines, course readings, addresses and such. VC has been recognized as a fundamental portion of insights in both psychometric hypotheses (Guilford 1967; Thurstone 1938; Vernon 1971) and information-processing theories (Carroll 1976: Hunt 1978: Sternberg 1980). It has some variety of aliases, and it has been a major topic of differential and experimental psychology research for many years (Sternberg et al., 1982). The PR Index (PRI) is one of four derived indices from the Wechsler Intelligence Scale for Children, 4th edition (Wechsler, 2003). Its essential reason is to look at nonverbal liquid thinking abilities (mental operations utilized to look at novel issues, organize considerations, look at rules and consistent connections, and make and test arrangements). Additionally, the PRI provides a direct assessment of cognitive processes including visual perception, visual-motor integration, visuospatial processing and coordination, and, to a lesser extent than its predecessor, mental/manual quickness and efficiency (Dowell \& Mahone, 2011).

WM is the capacity to preserve and control data over seconds, it is the central to cognition and it is impeded in numerous clinical communities (Zacharopoulos et al., 2020). WM is our ability to maintain and manipulate information over seconds (Baddeley, 1986), and individual differences in WM capacity are large and seem to be highly stable over time (Kane \& Engle, 2002). WM is a pivotal factor for cognition (Conway et al., 2003; Süß et al., 2002). Person variety in WM could be vital in a wide extent of cognitive spaces such as: counting thinking, consideration, arithmetic and language comprehension (Alloway and Alloway, 2010; Conway et al., 2003). WM capacity is a main factor of cognitive functioning and, consequently, WM capacity limitations impair cognitive functioning (Zacharopoulos et al., 2020). WM). PS have been discussed as important covariates of individual differences in intelligence. PS is considered as a multi-dimensional factor that is representative of one's cognitive performance in a designated amount of time and it is also highly related to WM (Kim \& Park, 2018). The Eye-test could be a brief test of social cognition, particularly mental state acknowledgment or "cognitive empathy," developed as a psychometric test for grown-ups within the common population (Baron-Cohen et al. 2001). The first version of the test was developed in 1997 and revised and expanded in 2001 (Warrier \& Baron-cohen, 2017). The Faux Pas Test is a psychological evaluation test that allows us to assess the degree of adaptation and social understanding through the interpretation of social situations, it allows us to assess empathy and understanding of other people's mental state (Gil et al., 2012). WM is the capacity of the subject to retain and store information, and is associated with the possibility of manipulating the information retained, modifying it and creating new information to respond to the demands of the environment. PR allows for practical constructive skills, the formation and classification of non-verbal concepts, visual analysis and simultaneous processing. The SP allows the focusing of stimuli, exploring, ordering elements of the environment quickly and effectively. VC allows the creation and relation of verbal concepts, it is associated with the richness of the lexical component, understanding the pragmatic component of language. 


\section{Results and Discussion}

Figure 2 and Figure 3 presents the results for each of the genders (men and women offendlers) respectively:

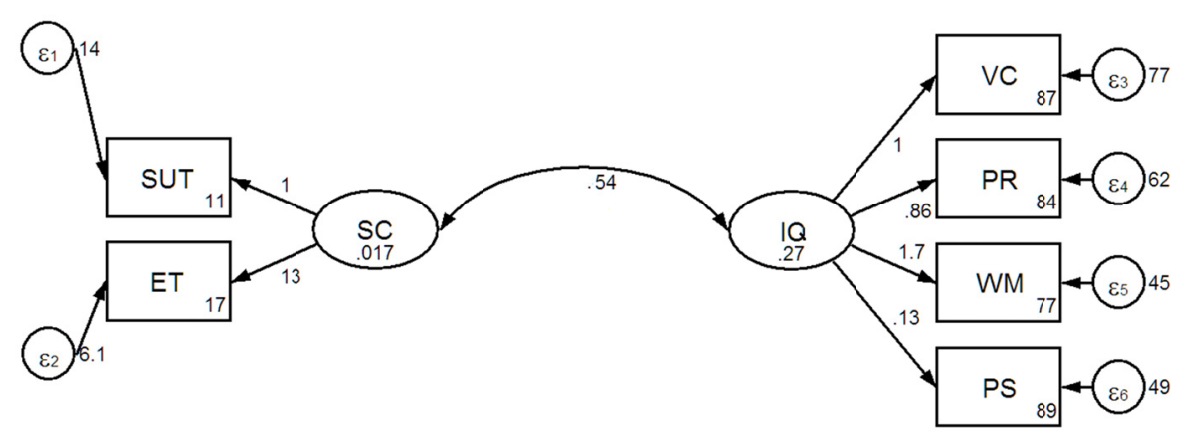

Figure 2. SEM - Men offenders. Source: Authors elaboration

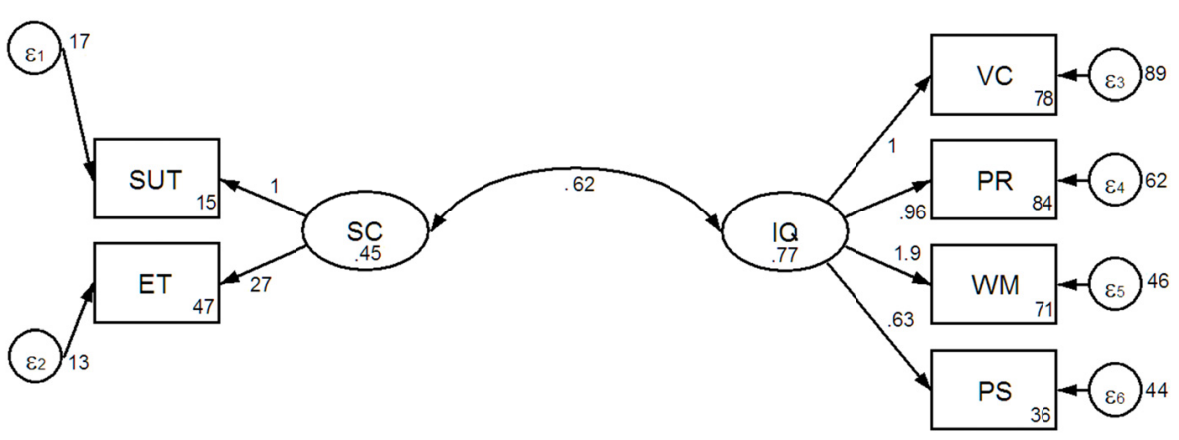

Figure 3. SEM - Women offenders. Source: authors elaboration

The results show that the correlation between IQ and SC is different. In the case of women offenders $\sigma x y=0.62$, in the case of men offenders $\sigma x y=0.54$. In both genders the WM variable has the greatest influence on IQ, similarly, the Eye-test with the greatest influence on SC. These results are due to the fact that the men offenderss present more externalizing behaviors that are explained from phylogenies, therefore, they will have more difficulties with the control of the impulses and all the handling of the emotions (Wetterborg et al., 2020). Female offenders have more internalizing behavior, it is more common for them to develop depressive and anxiety disorders (Bahreini et al., 2019). The measurements made that allowed the construction of the structural equation model approve the establishment of different neurocognitive profiles in men and women with ASPD. In relation to the IQ indices proposed by Wechsler, men with APD have a higher total IQ than women with APD (IQ). The cognitive performance of men with ASPD was higher on indices of WM, PR, and PS. Women with ASPD performed better on the VC index. ASPD has the adequate capacity of visual-motor coordination, they are able to group simple visual information in categories with common characteristics, they have good perception. In the execution of short term memory that requires mental manipulation and attention, they have some difficulties in adequately codifying new information, referring to retention, organization and manipulation of data that requires formation of concepts and complex reasoning skills, affecting learning in general. In the speed of processing, difficulties are observed in adequately processing visual information that involves attention and complex reasoning. They execute the task with little inhibitory control, however they do it quickly with ineffective results (Martin et al., 2019). They have little knowledge of concept formation, their verbal fluency is very limited, they understand basic words, and manage and construct concrete verbal explanations (Trahan \& Babcock, 2019).

Women with ASPD showed adequate performance in VC. This indicates skills to group information in a systematic and orderly way, with knowledge about concept formation, good verbal fluency. They have difficulties in adequately coding new information. They have an elementary capacity in visual-motor coordination, they manage to group in a very basic way visual information in categories with common characteristics, they have little visual perception and discrimination, the analysis and synthesis of abstract visual stimuli are low; they do not achieve the formation of non-verbal concepts, abstract rules, generalizations, and logical relationships, they present low PS in tasks that involve sustained and divided attention that require concept formation and complex 
reasoning skills (Sher et al., 2019). Performance on SC tests was poor in both groups tested, with worse performance in men with PAD. This allows us to establish that there is a direct relationship between deficits in SC and antisocial personality structure. Both groups present difficulties in recognizing the emotion they are experiencing in the eyes of the other. Women with ASPD present greater difficulties than men with ASPD in the recognition of facial features of happiness, sadness, and fear, emotions that have been associated with empathic responses and social behaviors (McKeown \& Thomson, 2019). Men with ASPD present inconsistencies in the recognition of facial expressions of disgust, as a consequence of failures to integrate emotion with context. They have greater deficiencies in emotional control presenting selective deterioration in responses related to empathy associated with negative emotions, becoming a predisposing factor to develop criminal behavior (de Pacual et al., 2020). Emotional instability, that is, lack of self-control and impulsive situations that cause tension, is a strong predictor of aggressive behavior in young offenders, present in both groups evaluated, with worse performance in men with ASPD. Both groups show defective moral judgment and deficits in perceiving social signals, giving social responses not for ethical and moral reasoning but profit or pleasure (Williams et al., 2020). Table 3 presents the results of the model fit for men and women offenders:

Table 3. Analyze model fit

\begin{tabular}{|c|c|c|}
\hline & Men & Women \\
\hline Lavaan 0.6-5 ended normally after & 72 iterations & 68 iterations \\
\hline Number of observations & 60 & 60 \\
\hline Estimator & ML & ML \\
\hline Optimization method & NLMINB & NLMINB \\
\hline Number of free parameters & 13 & 13 \\
\hline \multicolumn{3}{|l|}{ Model Test User Model: } \\
\hline Test statistic & 4.026 & 4.026 \\
\hline Degrees of freedom & 8 & 8 \\
\hline P-value (Chi-square) & 0.855 & 0.945 \\
\hline \multicolumn{3}{|l|}{ Model Test Baseline Model: } \\
\hline Test statistic & 20.175 & 21.275 \\
\hline Degrees of freedom & 60 & 60 \\
\hline P-value & 0.165 & 0.205 \\
\hline \multicolumn{3}{|l|}{ User Model versus Baseline Model: } \\
\hline Comparative Fit Index (CFI) & 1.000 & 1.000 \\
\hline Tucker-Lewis Index (TLI) & 2.440 & 3.540 \\
\hline \multicolumn{3}{|l|}{ Log Likelihood and Information Criteria: } \\
\hline Log Likelihood user model (H0) & -518.216 & -418.216 \\
\hline Log Likelihood unrestricted model (H1) & -516.203 & -416.203 \\
\hline Akaike (AIC) & 1062.432 & 1192.432 \\
\hline Bayesian (BIC) & 1080.647 & 1089.647 \\
\hline Sample-size adjusted Bayesian (BIC) & 1040.172 & 1064.172 \\
\hline \multicolumn{3}{|l|}{ Root Mean Square Error of Approximation: } \\
\hline RMSEA & 0.000 & 0.000 \\
\hline 90 Percent confidence interval - lower & 0.000 & 0.000 \\
\hline 90 Percent confidence interval - upper & 0.117 & 0.127 \\
\hline P-value RMSEA $<=0.05$ & 0.880 & 0.980 \\
\hline \multicolumn{3}{|l|}{ Standardized Root Mean Square Residual: } \\
\hline SRMR & 0.061 & 0.091 \\
\hline
\end{tabular}

Source: authors elaboration 
The AIC for men and women are 1062 and 1192 respectively and the chi-square 0.855 and 0.945 respectively. The chi square is low for both models, which means that the two models are doing a good job of reproducing the hypothetical relationship based on our data set. This allows us to accept the research hypothesis. SC is a concept introduced by neurosciences, to refer to a neuropsychological process that has been studied during the last years in several clinical conditions such as schizophrenia, dementia, autism, attention deficiencies, behavioral and antisocial disorders. It is conceptualized as the competencies that a subject has to carry out emotional processing, interpreting the intentions and beliefs of other people in social situations (Christidi, Migliaccio, Santamaria-Garcia, Santangelo; Muñoz, Currea, Diaz, \& Poveda, 2019). The neuroanatomy SC is explained by multiple neuronal connections of cortical and subcortical structures, with the predominance of the frontal lobe, specifically prefrontal. Through this concept, the neurobiology of the responses of empathy, sympathy, and moral reasoning is studied through the evaluation of the recognition of the gaze, the perspective of the other, and the internalization of the social rules (Decety \& Meyer, 2008). For its part, the IQ is a general assessment of intelligence, which is obtained with the results of standardized tests designed for this purpose. One of the main tools for the diagnosis of intellectual capacity in adolescents and adults has been the Weschler scales, particularly the WAISC IV test. Total IQ is estimated by evaluating four indices; WM, PR, PS, and VC.

Sympathy is defined by Daniel et al. (2014) as an emotional response of grief or concern for the welfare of others, favoring the development and attainment of higher levels of moral reasoning. In young offenders there is a modification in the subjective perception of the pain that they infringe on people, this is reflected in a different functioning in the amygdala, in the prefrontal dorsolateral prefrontal and ventromedial cortex. In addition, subtly differentiated neural mechanisms supporting empathy and sympathy are evident, demonstrating the relevance of a neurobiological approach in the development of moral neuroscience (Decety \& Michalska, 2010). Yoder and Decety (2018) carried out studies with magnetic resonance imaging simulating real crime situations to generate feelings of sympathy in the people who participated. They established that the medial prefrontal cortex is in charge of regulating behavior associated with collaborative situations, moral behavior, and social aggression, which is activated in the face of rule violations. This structure relates to areas of stimulus-focused responses, emotional and motor expressions, and WM. The frontal dorsomedial structure has as function the codifications and evocations of social stimuli. The prefrontal ventromedial area is the place where the understanding of other people's emotions originates, giving emotional values to the behaviors that are processed at a dorsolateral level.

The inhibition of negative emotional stimuli and the cerebral processing of acts of infringement of ethical rules are associated with the orbitofrontal cortex. It also evaluates the importance of emotion processing in making a decision and intervenes in the manifestations of anger and inhibitory responses. The insula intervenes in the understanding of signals with emotional content, facilitating decision making, and the elucidation of facial expressions. The cincture allows us to imagine emotional situations. The somatosensory cortex forms perceptual representations of the stimulus to generate a perspective of events and is associated with prefrontal areas for conscious decision making. The temporal pole intervenes in elaborating the basic moral judgment. The recognition of familiar faces and the facial expression of fear is associated with the upper temporal and fusiform turns. The behaviors of morality are related to the striated-ventral body. The amygdala participates in processing basic and social emotions.

Eimontaite et al. (2019) studied the functional neuroanatomy of cooperative responses in the prison population. The results showed that the levels of cooperation are motivated by sympathy and identified an activation on the left side of the putamen in the tomography, likewise the amygdala and the hippocampus also intervene in the cooperation process. Finally, they found that the disruption of the connection between the amygdala, hippocampus, and putamen is associated with emotionally motivated actions such as anger. For their part, the authors Bertone, Salvador, Aristizabal, Vallejos and Muniello (2017) analyzed empathy and its neuroanatomical components, explaining the relationship between problem behavior and mental illness, generally observed in adolescents and adults, using methods such as neuroimaging to access areas of the brain through observation to understand how the perception of distress and pain is activated in others. Empathy is immersed in cognitive skills, directed by executive function, mentalization, and language; these facilitate the increase in the scale of behaviors that motivate empathic responses (Decety, 2011; Koenigs et al., 2018). Other works with the same type of population indicate that cognitive functioning in offenders affects their susceptibility to specialized interventions (Wallinius, Nordholm, Wagnström, \& Billstedt, 2019). Norman, Smith, \& Decety (2017) state that empathy involves feeling what another person feels, identifying what others feel, and responding accordingly to the other's subjective states. Fede et al. (2016) and Sethic, O'Nions, Bird, McCurry, Viding (2018) define it as a complex cognitive process that involves deliberately embracing the emotional states of the other, in order to understand what they feel and think. 
Salvador, Bertone, Díaz, Muniello, and Vallejos (2017) propose that empathy is carried out by a diversity of brain structures and systems that interact among them: the brain stem, the amygdala, the hypothalamus, the striatum, the insula, the anterior cingulate cortex and the frontal orbital cortex (Hasson et al., 2017). It also covers the autonomic nervous system, neuroendocrine processes involved in social behaviors and emotional states, concluding that empathy is a cognitive process associated with multiple neuroanatomical structures. Pino et al. (2019) studied the recognition of emotion in a group of FI and a control group, concluding that FI present inconsistencies in the recognition of facial expressions of displeasure, as a consequence of failures in the integration of emotion with context. Bertone et al. (2017) studied the differences in SC in prisoners with mental health problems, such as psychosis and antisocial personality, compared to a control group, using the following neuropsychological tools: "Hinting task" (Gil, García, Carmona, Ortega, \& Campos, 2018), "Reading the mind in the eyes test" (Baron-Cohen, Jolliffe, Mortimore, \& Robertson, 1997), and "Cambridge mind-reading test" (Golan, Baron, \& Hill, 2006). They found that the subjects with psychosis scored statistically lower than the antisocial and control groups on a test of moral reasoning, but using emotional recognition tests, both individuals with psychotic personality structure and antisocial subjects performed worse than the control group.

Gehrer, Scheeff, Jusyte \& Schönenberg (2019) found it difficult for young offenders with psychopathy criteria to recognize in the gaze of the other the emotions that others may experience, these analyses were supported by standardized psychological tests. This study is in line with that explored by Pijper et al. (2018), in offenders with a diagnosis of conduct disorder, with a sample of 38 adolescents with a clinical diagnosis and a control group of 18 participants. They implemented as a methodology the use of video clips to generate empathic reactions, identifying that emotional regulation is a factor of empathy mainly in subjects who are highly sensitive to negative emotions. They exposed that offenders with conduct disorder have a deficient emotional control presenting selective deterioration in the responses related to empathy associated with negative emotions, becoming a predisposing factor to develop criminal behavior in adolescence that may worsen the problem. On the other hand, other studies have considered that facial expression has a relevant role in contributing to the exchange of social and affective information. Moreover, they are a type of stimuli associated with the activation of subcortical and cortical areas. Facial recognition is associated with areas of the lower and middle occipital, the fusiform gyrus, and the upper temporal sulcus (Kielh, Skelly, Decety, \& Yoder 2014).

In the work done by Blair (2010) about neuronal processing of emotions in psychopaths, they found that young people with the traits of psychopathy and behavioral problems have deficiencies in the regions associated with empathic pain as the pain represented increased; these areas included the anterior rostral cingulate cortex, the ventral striatum, and the amygdala, resulting in that the population with disruptive behavior showed a lower capacity of response to pain stimuli and their capacity for empathy, contributing to behavioral problems of this type of population. Authors such as Kanske, Winter, Bermpohl, Singer, and Spengle (2017) stated in their research findings that aggression is not limited to individuals with personality disorders, but also to healthy individuals; they also link empathy and aggression with alexithymia, a personality trait that describes a difficulty in identifying and expressing one's emotional states. Arango, Rosa, Restrepo and Puerta (2018) investigated in the female population with behavioral problems the deficit of empathy and CS, the sample was 36 adolescents and a control group of 18, in the findings identified that women have a greater deficit in the recognition of facial features of happiness, sadness, and fear, emotions that have been associated with empathic responses and social behavior.

Also, they found that this population has slower emotional processing, limiting the coding of these emotions. Likewise, they stated in their work that empathy works as an inhibitory response to antisocial and aggressive behaviors because it influences the ability to feel, to understand the mental states of others. Moral Reasoning (MR) is explained using various neural networks containing the upper frontal groove, the amygdala, and the ventromedial prefrontal cortex; anatomical structures that favor communication between affective, cognitive and motivational states (Lockwool, 2016). MRI is a neurocognitive and neural mechanism responsible for making decisions about appropriate and useful attitudes or behaviors for society (Molenberghs, 2017). The prefrontal structures, temporoparietal junction, temporal pole, amygdala, and cingulate cortex are involved in making moral decisions, mainly in violent situations that may or may not be justified. The structure and functions of the orbitofrontal cortex can be divided into medial and lateral areas (Hardy, 2019). These papers have found that the medial area is associated with reward expectation while the orbitofrontal lateral cortex is more related to punishment assessment and ongoing behavior inhibition or change (Friedman, Rhee, Ross, Corley, \& Hewitt, 2018).

Flannigan, Pei, Burke, Frenzel \& Rasmussen (2017), investigated criminal behavior in FI. They used psychopathy scales and tests to evaluate cognitive processes and found that FI subjects with antisocial structure present faulty moral judgment and deficits in perceiving social signals. Emotional instability, lack of self-control, and 
impulsivity are situations that generate tension and maybe an important predictor of aggressive behavior (Ibáñez et al., 2019). Likewise, Decety, Pletti \& Paulus (2019) analyzed the correlation between moral identity and neurocognitive mechanisms in a sample of 75 people, 40 of whom used the Chicago Moral Sensitivity Test (Aquino \& Reed, 2002), a German test on the moral self (Perugini \& Leone, 2009) and the electroencephalogram, showing that situations with moral content are processed at a cerebral level through various stages and that these components intervene in the discrimination of prosocial and antisocial scenes that are present in both children and adults. In the work carried out by Ward, Biggart, Larsson, and Shofield (2015), on the neuroscience of morality and social decision-making, they used techniques from neuroscience and psychology to make a prognosis of antisocial activities and evaluate the effectiveness of resocialization programs. Irregularities in neuronal activity were evidenced, mainly in structures such as the amygdala, increased striated muscle, and irregular connectivity throughout the cerebral cortex during a resting state, confirming a close relationship between criminal behavior and neuroanatomical involvement (Batson, Lamm, \& Decety 2007; Howar \& Decety 2013).

Decety et al. (2016) studied how stimulant use in FI affects moral processing, its influence on antisocial behavior and decreased empathy; they established a sample of 211 people, using instruments such as the moral task (Schaich, Sinnott-Armstrong, Calhoun, \& Kiehl, 2011), the addiction index (McLellan et al., 1992), and magnetic resonance imaging. The findings showed that at the time of making moral decisions, users of stimulant substances obtained a decrease in the hemodynamic activity of the amygdala compared to those who did not consume them, thus posing that the amygdala is the center where emotional information is judged during moral processing, Thus, decision making, antisocial behavior in stimulant users may be related to deficiencies in the functioning of the neural network responsible for assessing and making decisions about moral situations where frontal and cortical limbic areas are involved leading to risk and impulsivity decisions.

The active consumption of stimulants generates difficulties in the identification of emotions, for oneself and others. Also, they identified that the use of stimulants decreases levels of empathy and perspective-taking. Therefore, individuals with psychotic disorders with antisocial tendencies may form a high-risk group according to Koenigs et al. (2017), who compared behavioral and neuroanatomical functioning of CS in psychotic offenders with and without a history of suicide with non-offending community members. The findings indicated that reduced empathic accuracy and reduced gray matter in bilateral temporal lobes affect cognitive and social abilities, being a predisposing factor to suicide and to engaging in aggressive acts and situations towards others. In the work carried out by Samper et al. (2017) on prosocial reasoning in $220 \mathrm{FI}$ and a control group, hedonistic reasoning, reasoning oriented to the approval of others, empathic concern, state of anger, and prosocial behavior were evaluated. They found significantly higher scores in the FI group, in addition to greater emotional fluctuation, more anger, and aggressive physical and verbal behavior; while the control group scored better on empathy and prosocial behavior (Hyde, Murray, Shaw, \& Forbes 2017).

\section{Limitations}

In the development of this research there were no problems or difficulties.

\section{Recommendations}

Future research may focus on examining other types of neurodevelopmental disorders in this type of population.

\section{Conclusions}

In men and women offenders with ASPD, there is a direct relationship between deficits in SC and IQ, this type of population has neurocognitive functioning that is more severely impaired than non-offending youth. The correlation is higher in women offenders with ASPD. Men offenders have a higher IQ than women because of better results in WM rates, perceptive reasoning, and speed of information processing. Women perform better on the VC index. Associated to SC they have very similar characteristics, they show deficiencies at the level of prefrontal cortex myelination, women have more difficulties to recognize expressions of fear, anguish. Men have more difficulties to recognize expressions associated with irritability, aggressiveness, and violence. The premature presence of criminal and delinquent behavior reinforces the possibility that they will continue to be evident in adulthood. Emotional instability, lack of self-control and stressful situations of impulsivity, is a strong predictor of aggressive behavior in delinquent and non- delinquent youth, while state distress also affects those who have committed a crime, uncontrolled emotions are strong predictors of aggressive behavior in adolescence, but play a more important role in the sample of young offenders. 


\section{References}

Alloway, T. P., \& Alloway, R. G. (2010). Investigating the predictive roles of working memory and IQ in academic attainment. Journal of experimental child psychology, 106(1), 20-29. https://doi.org/10.1016/j.jecp.2009.11.003

Aquino, K., \& Reed, I. I. (2002). The self-importance of moral identity. Journal of personality and social psychology, 83(6), 1423. https://doi.org/10.1037/0022-3514.83.6.1423

Bahreini, Z., Keshvari, B., \& Farnam, A. (2019). The predictive role of alexithymia in marital satisfaction and forgiveness among women with antisocial personality. SALAMAT IJTIMAI (Community Health), 6(2), 208-216.

Baliousis, M., Duggan, C., McCarthy, L., Huband, N., \& Völlm, B. (2019). Executive function, attention, and memory deficits in antisocial personality disorder and psychopathy. Psychiatry Research, 278 (September 2018), 151-161. https://doi.org/10.1016/j.psychres.2019.05.046

De Pacual, A. S., Garre, P. S., \& Soler, C. L. (2020). Mental health in people with substance use disorder: differential aspects between men and women. Anales De Psicologia/Annals of Psychology, 36(3), 443-450. https://doi.org/10.6018/analesps.399291

DeLisi, M., Drury, A. J., \& Elbert, M. J. (2019). The etiology of antisocial personality disorder: The differential roles of adverse childhood experiences and childhood psychopathology. Comprehensive Psychiatry, 92, 1-6. https://doi.org/10.1016/j.comppsych.2019.04.001

Di Tella, M., Miti, F., Ardito, R. B., \& Adenzato, M. (2020). Social cognition and sex: Are men and women really different? Personality and Individual Differences, 162, 110045. https://doi.org/10.1016/j.paid.2020.110045

Dowell, L. R., \& Mahone, E. M. (2011). Perceptual Reasoning Index BT-Encyclopedia of Clinical Neuropsychology (J. S. Kreutzer, J. DeLuca, \& B. Caplan (eds.); pp. 1903-1907). Springer New York. https://doi.org/10.1007/978-0-387-79948-3_1582

Duclos, H., Desgranges, B., Eustache, F., \& Laisney, M. (2018). Impairment of social cognition in neurological diseases. Revue Neurologique, 174(4), 190-198. https://doi.org/10.1016/j.neurol.2018.03.003

Freeman, J. (2012). The relationship between lower intelligence, crime and custodial outcomes: a brief literary review of a vulnerable group. Vulnerable Groups \& Inclusion, 3(1), 14834. https://doi.org/10.3402/vgi.v3i0.14834

Kaya, S., Yildirim, H., \& Atmaca, M. (2020). Reduced hippocampus and amygdala volumes in antisocial personality disorder. Journal of Clinical Neuroscience, 75, 199-203. https://doi.org/10.1016/j.jocn.2020.01.048

Kim, S. J., \& Park, E. H. (2018). Relationship of working memory, processing speed, and fluid reasoning in psychiatric patients. Psychiatry Investigation, 15(12), 1154-1161. https://doi.org/10.30773/PI.2018.10.10.2

Kratcoski, P. C., Kratcoski, L. D., \& Kratcoski, P. C. (2020). Social-Psychological Theories of Delinquency. In Juvenile Delinquency (pp. 51-70). Springer. https://doi.org/10.1007/978-3-030-31452-1_3

Lebuda, I., Karwowski, M., Galang, A. J. R., Szumski, G., \& Firkowska-Mankiewicz, A. (2019). Personality predictors of creative achievement and lawbreaking behavior. Current Psychology, 1-10. https://doi.org/10.1007/s12144-019-00306-w

Martin, S., Zabala, C., Del-Monte, J., Graziani, P., Aizpurua, E., Barry, T. J., \& Ricarte, J. (2019). Examining the relationships between impulsivity, aggression, and recidivism for prisoners with antisocial personality disorder. Aggression and Violent Behavior, 49, 101314. https://doi.org/10.1016/j.avb.2019.07.009

Mayo Clinic. (2020). Antisocial personality disorder. Retrieved from https://www.mayoclinic.org/es-es/diseases-conditions/antisocial-personality-disorder/symptoms-causes/syc20353928

McKeown, A., \& Thomson, N. D. (2019). Psychopathy and intelligence in high-risk violent women. The Journal of Forensic Psychiatry \& Psychology, 30(3), 484-495. https://doi.org/10.1080/14789949.2018.1560487

Mirabel, H., Guinet, V., Voltzenlogel, V., Pradier, S., \& Hennion, S. (2020). Social cognition in epilepsy: State of the art and perspectives. Revue Neurologique, 176(6), 468-479. https://doi.org/10.1016/j.neurol.2020.02.010 
Ogilvie, J. M., Stewart, A. L., Chan, R. C. K., \& Shum, D. H. K. (2011). Neuropsychological measures of executive function and antisocial behavior: A meta-analysis. Criminology, 49(4), 1063-1107. https://doi.org/10.1111/j.1745-9125.2011.00252.x

Quintero-López, C., Gil-Vera, V. D., Bustamante-Hernández, A., \& De Ángel-Martínez, L. E. (2020). A Comparative Analysis of the Anxiety in Offenders of the Law Based on Structural Equational Models. Modern Applied Science, 14(2). https://doi.org/10.5539/mas.v14n2p65

Sher, L., Rutter, S. B., New, A. S., Siever, L. J., \& Hazlett, E. A. (2019). Gender differences and similarities in aggression, suicidal behaviour, and psychiatric comorbidity in borderline personality disorder. Acta Psychiatrica Scandinavica, 139(2), 145-153. https://doi.org/10.1111/acps.12981

Sternberg, R. J., Powell, J. S., \& Kaye, D. B. (1982). The nature of verbal comprehension. Poetics, 11(2), 155-187. https://doi.org/10.1016/0304-422X(82)90031-6

Trahan, L. H., \& Babcock, J. C. (2019). Emotional reactivity of partner violent men with personality disorder during conflict. Journal of Family Violence, 34(7), 645-654. https://doi.org/10.1007/s10896-019-00069-9

Warrier, V., \& Baron-cohen, S. (2017). Encyclopedia of Personality and Individual Differences. https://doi.org/10.1007/978-3-319-28099-8

Wetterborg, D., Dehlbom, P., Långström, N., Andersson, G., Fruzzetti, A. E., \& Enebrink, P. (2020). Dialectical behavior therapy for men with borderline personality disorder and antisocial behavior: A clinical trial. Journal of Personality Disorders, 34(1), 22-39. https://doi.org/10.1521/pedi_2018_32_379

Williams, M., Baskin-Sommers, A. R., Xian, H., Wirth, L., Scherrer, J. F., Volberg, R. A., Slutske, W. S., Kraus, S. W., Eisen, S. A., \& Potenza, M. N. (2020). Examining Relations Between Obsessive-Compulsive Features, Substance-Use Disorders, and Antisocial Personality Disorder in the Vietnam Era Twin Cohort. INTERNATIONAL JOURNAL OF MENTAL HEALTH AND ADDICTION. https://doi.org/10.1007/s11469-020-00299-9

Wojciechowski, T. W. (2019). Post-traumatic stress disorder and having antisocial peers in adolescence are risk factors for the development of antisocial personality disorder. Psychiatry Research, 274, 263-268. https://doi.org/10.1016/j.psychres.2019.02.053

Zacharopoulos, G., Klingberg, T., \& Cohen Kadosh, R. (2020). Cortical surface area of the left frontal pole is associated with visuospatial working memory capacity. Neuropsychologia, 143, 107486. https://doi.org/10.1016/j.neuropsychologia.2020.107486

\section{Copyrights}

Copyright for this article is retained by the author(s), with first publication rights granted to the journal.

This is an open-access article distributed under the terms and conditions of the Creative Commons Attribution license (http://creativecommons.org/licenses/by/4.0/). 